\title{
Aromaterapi Lavender dapat Menurunkan Intensitas Nyeri Perineum pada Ibu Post Partum
}

\author{
Wiwin Widayani \\ DIII Kebidanan Poltekkes Kemenkes Bandung \\ Jalan Pajajaran No.56, Pasir Kaliki, Cicendo, Kota Bandung, Jawa Barat 40171 \\ Email: wiwinbidbdg@gmail.com
}

\begin{abstract}
Abstrak
Nyeri perineum dapat memengaruhi kemampuan wanita untuk mobilisasi sehingga dapat menimbulkan komplikasi seperti perdarahan post partum. Trauma pada perineum juga menimbulkan rasa tidak nyaman dan nyeri saat melakukan hubungan seksual. Karena itu, penanganan nyeri perineum ini penting dilakukan. Saat ini penanganan yang sering digunakan yaitu terapi komplementer aromaterapi dengan minyak essensial lavender, karena lavender mempunyai sifat antikonvulsan, antidepresi, anxiolytic, dan menenangkan. Aromaterapi akan menstimulasi hipotalamus untuk mengeluarkan mediator kimia yang berfungsi sebagai penghilang rasa sakit dan menimbulkan perasaan bahagia. Tujuan penelitian ini adalah untuk mengetahui pengaruh aromaterapi lavender terhadap intensitas nyeri luka jahitan perineum pada ibu post partum. Penelitian ini merupakan quasi eksperiment pre and post control pada ibu nifas yang berada di Bidan Praktik Mandiri Wilayah Kota Bandung. Pengambilan sampel penelitian ini menggunakan teknik consecutive sampling. Data diambil dengan menggunakan instumen yang diadaptasi dari Visual Analog Scale (VAS) dengan analisis uji wilcoxon. Hasil penelitian menunjukkan ada penurunan nyeri sebelum dan setelah pemberian aromaterapi lavender secara inhalasi $(Z=-3,77)$ dengan $p$-value 0,001. Aromaterapi lavender dapat menjadi alternatif terapi komplementer untuk menurunkan nyeri pada ibu post partum akan tetapi diperlukan penelitian lebih lanjut dengan responden yang lebih banyak.
\end{abstract}

Kata Kunci: aromaterapi lavender, nyeri perineum

\section{Lavender Aromatherapy Reduced the Intensity of Perineal Pain among Post Partum Women}

\begin{abstract}
Perineals pain affects woman ability to mobilize so that it can cause complications such as post-partum hemorrhagic. Trauma to the perineum also cause discomfort and dyspareunia, therefore, perineal pain management is important. Currently the handling used to relieve pain is complementary therapy aromatherapy with essential oils of lavender, because lavender has the properties of anticonvulsant, antidepressant, anxiolytic, and also soothing. Aromatherapy stimulates the hypothalamus to secrete chemical mediators that serve as pain relievers and give rise to feelings of happiness. The purpose of this study was to determine the effect of lavender aromatherapy to the perineal pain intensity in post partum women. This study was a quasi experiment pre and post non random control in postpartum women at Bidan Praktik Mandiri in Bandung. This study used was consecutive sampling technique. The data were taken using the instrument adapted from a Visual Analog Scale (VAS) and analyzed by the wilcoxon signed rank test. The result showed that there was a decrease in pain intensity before and after the administration of inhaled lavender aromatherapy $(Z=-3.77)$ with p-value 0.001. Lavender aromatherapy can be a complementary alternative therapy to reduce pain in postpartum women but more research necessary is needed with more respondents.
\end{abstract}

Keywords: lavender aromatherapy, perineum pain

Info Artikel:

Artikel dikirim pada 21 September 2016

Artikel diterima pada 31 Oktober 2016

DOI : http://dx.doi.org/10.21927/jnki.2016.4(3).123-128 


\section{PENDAHULUAN}

Tanpa memperhatikan apakah perineum mengalami trauma atau tidak, seorang ibu cenderung merasakan adanya memar di sekitar vagina dan jaringan perineum selama beberapa hari setelah persalinan. Ibu yang mengalami laserasi perineum akan merasakan nyeri selama beberapa hari sampai penyembuhan terjadi (1).

Padabeberapaorang, nyeridapatmengganggu dibanding gangguan akibat penyakit yang lain. Setelah melahirkan secara pervaginam, seorang ibu sering melaporkan nyeri dan trauma pada perineum. Nyeri perineum merupakan hal yang fisiologis pada ibu post partum, akan tetapi nyeri ini memengaruhi kemampuan wanita untuk mobilisasi sehingga dapat menimbulkan komplikasi seperti perdarahan post partum. Nyeri perineum akibat adanya trauma seperti adanya laserasi perineum dapat menyebabkan rasa tidak nyaman dan dispareunia. Di Rumah Sakit Royal Victoria Australia dilaporkan bahwa $90 \%$ wanita mengalami nyeri perineum. Nyeri dirasakan ketika berjalan $(33 \%)$, duduk (39\%), dan tidur (45\%) $(2)$.

Hasil penelitian menjelaskan bahwa sebagian besar wanita menggunakan analgesia untuk mengatasi rasa sakit tersebut dengan menggunakan obat analgetik dan ice pack (69\%), oral analgesik (75\%) (2). Hal tersebut membuktikan bahwa nyeri perineum sangat mengganggu bagi sebagian besar wanita. Apabila kekhawatiran dan nyeri perineum berlangsung lama, maka dapat berdampak negatif terhadap fungsi dan pengalaman awal menjadi seorang ibu. Oleh karena itu, penanganan nyeri perineum ini penting untuk dilakukan.

Penanganan untuk mengurangi nyeri perineum dapat dilakukan secara farmakologi dan non farmakologi. Namun penggunaan secara farmakologi sering menimbulkan efek samping dan kadang tidak memiliki kekuatan efek yang diharapkan. Aromaterapi digunakan sebagai salah satu alternatif penanganan nyeri non farmakologik. Berbagai macam aroma terapi yang dapat digunakan antara lain cendana, kemangi, kayumanis, kenanga, sitrus, melati, cengkih, lavender, mawar, jasmine. Saat ini penanganan yang sering digunakan untuk mengurangi rasa nyeri yaitu terapi komplementer aromaterapi dengan minyak essensial lavender, karena lavender mempunyai sifat-sifat antikonvulsan, antidepresi, anxiolytic, dan bersifat menenangkan (3).
Saat aromaterapi dihisap, zat aktif yang terdapat di dalamnya akan merangsang hipotalamus (kelenjar hipofise) untuk mengeluarkan hormon endorpin. Endorpin diketahui sebagai zat yang menimbulkan rasa tenang, relaks dan bahagia. Di samping itu, zat aktif berupa linaool dan linalyl acetate yang terdapat dalam lavender berefek sebagai analgetik $(4,5)$.

Banyak penelitian melaporkan pengaruh aromaterapi lavender terhadap penurunan nyeri, tetapi pengaruh aromaterapi lavender terhadap nyeri perineum belum banyak. Vakilian melaporkan bahwa pemberian aromaterapi lavender dapat mengurangi nyeri perineum pada 60 ibu nifas yang mengalami laserasi spontan dan episiotomi, 40\% di antaranya dilaporkan tidak merasakan sakit. Dale \& Cornwell melaporkan nyeri perineum berkurang pada $635 \mathrm{ibu}$ post partum yang mandi dengan menambahkan minyak lavender (6). Oleh karena itu, perlu dilakukan penelitian pengaruh aromaterapi lavender terhadap penurunan nyeri luka jahitan perineum ibu post partum.

\section{BAHAN DAN METODE}

Penelitian ini dilakukan dengan menggunakan penelitian quasi experiment dengan rancangan one group pre dan post test. Tempat penelitian adalah Bidan Praktik Mandiri (BPM) yang ada di wilayah Kota Bandung. Penelitian dilakukan mulai dari Bulan Mei sampai September 2015, dengan jumlah sampel 28 orang.

Teknik pengambilan sampel pada penelitian ini adalah dengan non probability sampling berupa teknik consecutive sampling yaitu dengan memilih sampel yang memenuhi kriteria penelitian sampai kurun waktu tertentu sehingga jumlah sampel terpenuhi.

Kriteria inklusi pada penelitian ini adalah ibu post partum hari ke 1 , ibu post partum yang melahirkan normal (pervaginam) dan mengalami rupture derajat 2, ibu post partum yang mengalami luka jahitan perineum. Sedangkan kriteria eksklusinya yaitu ibu post partum yang melahirkan dengan tindakan operasi atau vakum, ibu post partum yang mengalami vaginitis, hematoma dan abses di perineum, ibu post partumyang memiliki riwayatalergi obat, ibu post partum yang memiliki penyakit asma.

Intervensi dilakukan setelah 2 jam dilakukan penjahitan perineum. Setelah mengisi kuesioner pretest, reponden diberikan intervensi aromaterapi lavender inhalasi dalam kurun waktu menit ke 
10, 30 dan 60, aromaterapi diberikan selama 10 menit. Kemudian dilakukan posttest seiring dengan observasi masa nifas 2 jam, dengan cara memeriksa luka jahitan perineum menggunakan pinset anatomis. Saat diperiksa luka jahitan, peneliti melihat reaksi wajah responden.

Instrumen yang digunakan yaitu Visual Analogue Scala (VAS) dengan skala nyeri 0-10, dengan batasan kategori nyeri diadaptasi ke dalam Bahasa Indonesia, yaitu tidak nyeri (0); nyeri ringan (1-3); rasa nyeri seperti rasa gatal, rasa tersetrum, melilit, terpukul, perih, nyut-nyutan, kram; nyeri sedang (4-7); rasa nyeri seperti nyut-nyutan/ kram; nyeri berat (8-9): sangat nyeri, sulit bergerak tapi masih terkontrol; dan nyeri sangat berat (10): sangat nyeri, sulit bergerak sampai tidak terkontrol seperti menangis, menjerit.

Bahan yang digunakan adalah uap minyak lavender dengan konsentrasi $100 \%$, diberikan 4-5 tetes dilarutkan dalam $200 \mathrm{ml}$ air, diberikan secara inhalasi melalui vaporizer atau alat listrik. Sebelum inhalasi, cawan tungku aromaterapi yang telah diberikan air ditunggu sampai hangat baru diteteskan essens aromaterapi. Jarak antara tungku dengan responden kurang $30 \mathrm{~cm}$. Setelah tercium wangi aromaterapi, pasien diminta relaks dan menghirup wangi aromaterapi selama 10 menit. Responden dikondisikan dalam ruangan dengan ukuran antara 10-16 $\mathrm{m}^{2}$ dan tidak banyak ventilasi udara. Analisis data yang digunakan analisis univariat dan bivariat. Analisis bivariabel sebelum dan setelah diberikan perlakuan digunakan uji wilcoxon.

\section{HASIL DAN BAHASAN}

Berdasarkan Tabel 1 dapat diketahui bahwa karakteristik responden berdasarkan umur terbanyak adalah 20 -35 tahun $(71,4 \%)$ sedangkan karakteristik responden berdasarkan pekerjaan sebanyak $92,9 \%$ tidak bekerja. Berdasarkan pendidikan responden, terbanyak pada pendidikan SMA $(39,3 \%)$. Berdasarkan riwayat melahirkan, responden terbanyak pada pada riwayat melahirkan $\geq 2$ kali $(57,1 \%)$.
Tabel 1. Distribusi Frekuensi Nyeri Luka Jahitan Perineum Berdasarkan Karakteristik Responden

\begin{tabular}{lcc}
\hline \multicolumn{1}{c}{ Karakteristik } & $\mathbf{n}$ & $\%$ \\
\hline Usia & & \\
$\quad<20$ Tahun & 7 & 25 \\
20-35 tahun & 20 & 71,4 \\
$\quad$ >35 tahun & 1 & 3,6 \\
Pekerjaan & & \\
$\quad$ Tidak bekerja & 26 & 92,9 \\
$\quad$ Bekerja & 2 & 7,1 \\
Pendidikan & & \\
$\quad$ SD & 3 & 10,7 \\
SMP & 8 & 28,6 \\
SMA & 11 & 39,3 \\
$\quad$ Perguruan Tinggi & 6 & 21,4 \\
Paritas & & \\
$\quad$ Melahirkan 1 kali & 12 & 42,9 \\
$\quad$ Melahirkan $\geq 2$ kali & 16 & 57,1 \\
Jumlah & 28 & 100 \\
\hline
\end{tabular}

Sumber: Data Primer Tahun 2015

Tabel 2 di bawah ini merupakan frekuensi intensitas nyeri luka jahitan perineum sebelum dan sesudah intervensi.

Tabel 2. Distribusi Frekuensi Intensitas Nyeri Luka Jahitan Sebelum dan Sesudah Intervensi

\begin{tabular}{lcccc}
\hline \multirow{2}{*}{ Intensitas Nyeri } & \multicolumn{2}{c}{ Sebelum } & \multicolumn{2}{c}{ Sesudah } \\
\cline { 2 - 5 } & $\mathbf{n}$ & $\mathbf{\%}$ & $\mathbf{n}$ & $\%$ \\
\hline Tidak Nyeri & 2 & 7,1 & 7 & 25 \\
Nyeri Ringan & 6 & 21,4 & 11 & 39,3 \\
Nyeri Sedang & 10 & 35,7 & 9 & 32,1 \\
Nyeri Berat & 8 & 28,6 & 1 & 3,6 \\
Nyeri Sangat Berat & 2 & 7,1 & 0 & 0 \\
Jumlah & 28 & & 28 & \\
\hline
\end{tabular}

Sumber: Data Primer Tahun 2015

Berdasarkan Tabel 2 diketahui bahwa intensitas nyeri sebelum diberikan intervensi paling banyak berada pada nyeri sedang $(35,7 \%)$. Setelah diberikan intervensi, intensitas nyeri paling banyak menjadi nyeri ringan $(39,3 \%)$

Tabel 3 merupakan tabel perbedaan intensitas nyeri luka jahitan perineum sebelum dan sesudah diberikan aromaterapi lavender.

Tabel 3. Perbedaan Intensitas Nyeri Luka Jahitan Perineum Sebelum dan Sesudah Intervensi

\begin{tabular}{lccc}
\hline $\begin{array}{c}\text { Skor Intensitas } \\
\text { Nyeri Perineum }\end{array}$ & $\begin{array}{c}\text { Sebelum } \\
\text { Perlakuan } \\
(\mathbf{n}=28)\end{array}$ & $\begin{array}{c}\text { Sesudah } \\
\text { Perlakuan } \\
(\mathbf{n}=28)\end{array}$ & $\boldsymbol{p}$-value \\
\hline Median (Rentang) & $3,00(1-5)$ & $2,00(1-4)$ & $<0,001^{*}$ \\
\hline
\end{tabular}

Sumber: Data Primer Tahun 2015

*Uji Wilcoxon $(Z=-3,77)$ 
Pada Tabel 3 dapat diketahui bahwa nilai median dan rentang dari skor intensitas nyeri luka perineum setelah perlakuan menjadi lebih rendah dibandingkan sebelum perlakuan. Berdasarkan hasil uji statistik nilai $p<0,05$ sehingga terdapat perbedaan skor pada kelompok responden sebelum perlakuan dan setelah perlakuan. Oleh karena itu dapat diasumsikan bahwa pemberian aromaterapi lavender berpengaruh terhadap penurunan intensitas nyeri luka perineum.

Nyeri luka perineum akan dirasakan setelah persalinan sampai beberapa hari pasca persalinan. Bagi seorang perempuan kekuatan otot perineum sangat penting, karena robekan perineum yang terjadi selama proses persalinan dapat menyebabkan melemahnya otot-otot dasar panggul. Selain itu, robekan perineum dapat menyebabkan rasa tidak nyaman dan dispareunia. Hasil penelitian didapatkan bahwa responden mengalami nyeri sedang $(35,7 \%)$. Nyeri yang dirasakan ini dapat terjadi karena adanya proses penghantaran nyeri dari sel syaraf aferen atau neuron sensori, serabut konektor atau interneuron dan sel saraf eferen atau neuron motorik yang dihantarkan ke otak, sehingga dipersepsikan tubuh menjadi rasa nyeri.

Nyeri perineum dapat terjadi setelah persalinan pervaginam akibat laserasi spontan pada saat bayi lahir dan dapat diperparah apabila terdapat robekan pada perineum yang disebabkan tindakan episiotomi. Tindakan ini akan memerlukan penjahitan dan dengan penjahitan tersebut dapat menyebabkan nyeri pada daerah luka jahitan. Sebanyak $33 \%$ wanita mengalami nyeri perineum karena tindakan episiotomi dan 52\% merupakan laserasi spontan (7).

Pengurangan rasa nyeri luka jahitan perineum pada ibu post partum dilakukan dengan berbagai cara, salah satunya dengan pemberian inhalasi melalui aromaterapi lavender. Berdasarkan hasil penelitian bahwa terdapat perbedaan signifikan intensitas nyeri antara kelompok perlakuan dan kelompok kontrol dengan $p$-value 0,01 .

Sesuai hasil penelitian Stea Susana menunjukkan bahwa terapi esensial minyak lavender berpengaruh secara positif terhadap kecemasan insomnia dan mengontrol rasa sakit (8). Dengan demikian aromaterapi lavender dapat menjadi salah satu alternatif penanganan nyeri luka perineum yang dapat mengakibatkan kondisi fisik maupun psikologis ibu menjadi lebih baik. Begitu juga hasil penelitian Salamati didapatkan bahwa rasa sakit sebelum dan setelah menghirup minyak esensial lavender berpengaruh secara signifikan terhadap pengurangan rasa sakit dengan $p$-value $<0,05$ (9). Menurut Dochterman, aromaterapi adalah pemberian minyak esensial melalui metode massase, salep topikal, inhalasi, mandi kompres (panas, dingin) untuk mengurangi nyeri dan dapat menimbulkan efek relaksasi dan terapi pengobatan (7). Bentuk aromaterapi yang banyak digunakan untuk mengurangi rasa nyeri serta memiliki sifat antiseptiknya adalah lavender. Penelitian yang dilakukan Dale \& Cornwell pada 635 wanita yang pada kelompok pertama ditambahkan minyak lavender murni pada air mandi mereka sebanyak 6 tetes pada hari ke 10 pertama pascanatal. Pada hari kesepuluh wanita dan bidan menyelesaikan kuesioner mengenai nyeri perineum. Data yang diperoleh menunjukkan bahwa $90 \%$ ibu melaporkan merasa lebih baik setelah mandi menggunakan minyak lavender dan tidak ditemukan efek samping (10).

Kristanti menjelaskan bahwa molekul dan partikel lavender saat dihirup akan masuk melalui hidung, kemudian diterima oleh reseptor saraf sebagai signal yang baik dan kemudian diinterpretasikan sebagai bau yang menyenangkan, dan akhirnya sensori bau tersebut masuk serta memengaruhi sistem limbic sebagai pusat emosi seseorang, sehingga saraf dan pembuluh darah perasaan akan semakin relaks dan akhirnya rasa nyeri berkurang (11).

Dijelaskan juga oleh Pratiwi bahwa penurunan nyeri dengan aromaterapi lavender mengacu pada konsep gate control yang terletak pada fisiologi mekanisme penghantaran impuls nyeri yang terjadi saat sistem pertahanan dibuka, dan sebaliknya penghantaran impuls nyeri dapat dihambat saat sistem pertahanan ditutup. Aromaterapi lavender merupakan salah satu upaya untuk menutup sistem pertahanan tersebut. Selain itu, aromaterapi lavender memengaruhi kelancaran sirkulasi darah, sehingga suplai nutrisi ke jaringan luka tercukupi dan proses penyembuhan akan lebih cepat (12). Saat aromaterapi dihisap, zat aktif yang terdapat di dalamnya akan merangsang hipotalamus (kelenjar hipofise) untuk mengeluarkan hormon endorpin. Endorpin diketahui sebagai zat yang menimbulkan rasa tenang, relaks, dan bahagia. Di samping itu, zat aktif berupa linaool dan linalyl acetate yang terdapat dalam lavender berefek sebagai analgetik $(4,5)$.

Karlina dkk juga menjelaskan bahwa pemberian aromaterapi lavender terbukti dapat menurunkan 
intensitas nyeri persalinan fisiologis kala satu fase aktif. Begitu juga Kartika dkk menyebutkan bahwa terdapat perbedaan signifikan pada intensitas nyeri persalinan normal kala satu, sebelum dan sesudah diberikan lilin aromaterapi lavender. Hal ini membuktikan bahwa efek aromaterapi lavender yang memberikan rasa tenang dan analgetik sangat berpengaruh terhadap penurunan rasa nyeri. Seperti yang telah dijelaskan sebelumnya bahwa zat kimia yang dihasilkan dari hormon endorpin sebagai akibat rangsangan hipotalamus oleh aromaterapi lavender, dapat menghasilkan rasa tenang, rasa bahagia dan relaks, serta melemasakan otot-otot yang tegang akibat rasa nyeri, salah satunya melemaskan otototot perineum yang tegang karena rasa nyeri luka laserasi $(4,5,13,14)$.

\section{SIMPULAN DAN SARAN}

Terdapat penurunan intensitas nyeri luka jahitan perineum sebelum dan setelah diberikan aromaterapi lavender. Aromatepi lavender berpengaruh secara signifikan terhadap penurunan nyeri luka jahitan perineum pada ibu post partum dengan $p$-value 0,01 .

Inhalasi aromaterapi lavender dapat digunakan sebagai alternatif terapi komplementer pada ibu post partum dengan luka jahitan perineum. Diperlukan penelitan lebih lanjut dengan sampel yang lebih banyak dengan responden yang tidak hanya memiliki luka jahitan perineum derajat dua.

\section{RUJUKAN}

1. Fraser DM, Cooper MA. Myles Buku Ajar Bidan. Jakarta: EGC; 2009.

2. East CE, Sherburn M, Nagle C, Said J, Forster D. Perineal pain following childbirth: Prevalence, effects on postnatal recovery and analgesia usage. Midwifery [Internet]. 2012 Feb [cited 2015 Sep 10];28(1):93-7. Available from: http://linkinghub. elsevier.com/retrieve/pii/S0266613810001889.

3. Koensoemardiyah. Aromaterapi untuk Kesehatan dan Kecantikan. Yogyakarta: Lily Publisher; 2009.

4. Tournaire M, Theau-Yonneau A. Complementary and Alternative Approaches to Pain Relief during Labor. Evidence-Based Complement Altern Med [Internet]. 2007 [cited 2015 Jan 1];4(4):409-17. Available from: http://www.hindawi.com/journals/ ecam/2007/256475/abs/
5. Woollard AC, Tatham KC, Barker S. The influence of essential oils on the process of wound healing: a review of the current evidence. J Wound Care [Internet]. 2007 Jun;16(6):255-7. Available from: http://www.magonlinelibrary.com/doi/ abs/10.12968/jowc.2007.16.6.27064.

6. Vakilian K, Atarha M, Bekhradi R, Chaman R. Healing advantages of lavender essential oil during episiotomy recovery: A clinical trial. Complement Ther Clin Pract [Internet]. 2011 Feb;17(1):50-3. Available from: http://linkinghub. elsevier.com/retrieve/pii/S1744388110000381

7. Dochterman J. Nursing intervention Classification (NIC) fourth edition. USA: Mosby; 2004.

8. Stea S, Beraudi A, De Pasquale D. Essential Oils for Complementary Treatment of Surgical Patients: State of the Art. Evidence-Based ComplementAltern Med [Internet]. 2014;2014:1-6. Available from: http://www.hindawi.com/journals/ ecam/2014/726341/

9. Salamati A, Mashouf S, Sahbaei F, Mojab F. Effects of Inhalation of Lavender Essential Oil on Open-heart Surgery Pain. Iran J Pharm Res IJPR [Internet]. 2014;13(4):1257-61. Available from: http://www.ncbi.nlm.nih.gov/pubmed/25587315.

10. Koulivand PH, Khaleghi Ghadiri M, Gorji A. Lavender and the Nervous System. EvidenceBased Complement Altern Med [Internet]. 2013;2013:1-10. Available from: http://www. hindawi.com/journals/ecam/2013/681304/

11. Kristanti EE. Pengaruh Aropmaterapi Lavender Terhadap Penurunan Derajat Kecemasan pada Lansia di Panti Wredha St Yoseph Kediri. J Penelit Stikes RS Baptis Kediri [Internet]. 2010;3(2):94100. Available from: http://puslit2.petra.ac.id/ ejournal/index.php/stikes/article/view/18399.

12. Pratiwi R, Ermiati, Widiasih R. Penurunan Intensitas Nyeri Akibat Luka Post Sectio Caesarea Setelah Dilakukan latihan Teknik Relaksasi Pernapasan Menggunakan Aromaterapi Lavender di Rumah Sakit Al Islam Bandung. Students e-journals [Internet]. 2012;1(1):1-15. Available from: http:// jurnal.unpad.ac.id/ejournal/article/view/711.

13. Karlina SD, Reksohusodo S, Widayati A. Pengaruh Aromaterapi Lavender secara Inhalasi terhadap Penurunan Intensitas Nyeri Persalinan Fisiologis pada Primipara Inpartu Kala Satu Fase Aktif di BPM Fetty Fathiyah Kota Mataram. Maj Kesehat Fak Kedokt Univ Brawijaya [Internet]. 
2015;2(2). Available from: http://majalahfk.ub.ac. id/index.php/mkfkub/article/view/59.

14. Kartika R, Susilo J, Lestari P. Efek Lilin Aromaterapi Lavender Terhadap Perubahan
Intensitas Nyeri Persalinan Normal Kala I Fase Aktif. ejurnal Ngudi Waluyo [Internet]. 2015;7(24). Available from: http://ejournalnwu.ac.id/article/ view/1435905534. 